\title{
Adaptive engineering management tools of enterprise economic security
}

\author{
G.E. Krokhicheva ${ }^{a}$, V.V. Lesnyak ${ }^{b^{*}}$, E.M. Selezneva ${ }^{c}$ and E.S. Arakelyants ${ }^{d}$
}

${ }^{a}$ Krokhicheva Galina Egorovna, DSc of Economics, Professor, Chair of Economic Security, Accounting and Law, Don State Technical University, Rostov-on-Don, Russian Federation

${ }^{b}$ Lesnyak Vladimir Vladimirovich, PhD of Economics, Associate Professor, Chair of Economic Security, Accounting and Law, Don State Technical University, Rostov-on-Don, Russian Federation

'Selezneva Ekaterina Mikhaylovna, PhD of Economics, Associate Professor, Chair of Economic Security, Accounting and Law, Don State Technical University, Rostov-on-Don, Russian Federation

${ }^{d}$ Arakelyants Eduard Stepanovich, PhD of Economics, Associate Professor, Chair of Economic Security, Accounting and Law, Don State Technical University, Rostov-on-Don, Russian Federation

\section{CH R O N I C L E A B S T RACT}

Article history:

Received: November 26, 2017

Received in revised format: January 31,2018

Accepted: April 19, 2018

Available online:

April 19, 2018

Keywords:

Adaptation

Adaptive engineering tools

Economic security

Basic indicators of economic

security

\begin{abstract}
This paper discusses the organizational and methodological foundations and methods exploited to forecast, analyze and scale down threats and risks in the sphere of economic security, to solve the adaptation problems, to implement and to evaluate of the potency of protective measures. The object of the conducted research is associated with various economic activities of the commercial enterprises affiliated in Rostov region. A suggested model of the formation and functioning of adaptive engineering tools for managing economic security in the form of derivative balance of the enterprise resources and the sources of their formation will allow the proprietors, executive board and managerial staff to obtain necessary information within the requested context regarding the enterprise vital economic interests. In addition, the paper pays attention to the methodological aspects of accounting description and estimation of the iterative achievements to meet the desired adaptation results, implemented within the framework of the described iterative algorithm aimed at ensuring strategic prediction.
\end{abstract}

\section{Introduction}

The present situation in global economics is characterized with the increasing dynamism of the external environment of the enterprises functioning, the emergence of newly discovered challenges and threats to their security, growth of risks and toughening competition. Hence there is a need for developing and exploiting new accounting tools qualitatively and management mechanisms, for identifying the interrelationships between the changes and the threats associated with them, adaptation to the changes, and neutralization of possible threats and use of existing initiatives. Adaptation to the external environment and achievement of long-term success in an enterprise significantly depends on the development of appropriate strategies that should ensure the effective adaptation of the organization's strategy to the surrounding conditions, taking into account both the opportunities and the threats. The key to success

* Corresponding author. Tel.: +7988-532-11-32

E-mail address: lesnyak2005@rambler.ru (V.V. Lesnyak) 
is associated with the development of such a management strategy, in which the actions and organization's internal structure optimally meet external conditions. Even large corporations such as General Motors, IBM, PanAm are forced to fight for survival because their executive boards and governance were not able to cope with the changes taken place, and they were beaten by competitors who managed to adapt to a rapidly changing business environment (Shifrin, 2006). The qualitative solution of problems of adaptation, forecasting, identification and analysis of threats and risks in the field of economic security, implementation and evaluation of the effectiveness of protective measures and the security system in general involve the development of adequate methodological tools to assess the effectiveness of adaptive management processes and their correspondence to economic security basic indicators to ensure the best interests of enterprise proprietors, executive board, and managerial staff. Providing enterprise economic security is primarily connected with the protection of the interests of its proprietors. Property is a fundamental concept in economic security management, aimed at protecting property relationships and ensuring sustainable and dynamic development. In this regard, there arises a need for assessing the effectiveness of the utilization of the resources and the property to prevent threats and maintain safe functioning based on the use of new engineering methods, tools and technologies of an adaptive nature, providing the possibility of interactive modeling of the future and the selection of means to achieve it, a step-by-step approach to the desired adaptation state. The use of adaptive engineering tools is aimed at ensuring stable functioning, preventing economic catastrophes and bankruptcies, achieving the desired results, avoiding potential hazards, i.e., surviving in a changing environment, riskiness and uncertainty (Armstrong \& Mitchell, 2008).

The tasks of information support of management processes from the point of view of the accounting instruments used for these purposes have been solved to some extent for more than 400 years, since Luca Pacioli published the first descriptions of the double-entry system of book-keeping. Using doubleentry system of book-keeping allows obtaining data specifying assets, capital, liabilities, revenues, expenses and results, and, to exploit use this information in the management (Daft \& MacIntosh, 1978). Applying accounting and analytical information for management purposes implies a wide range of tasks to be solved. These tasks are: the existence of numerous options for information support of economic security management processes (traditional, engineering, integrated, disintegrated); classification and systematization of enlarged managed entities of the enterprise external macro and microenvironment; systematization of the company's resource potential; threats and challenges to economic security; risks in the sphere of economic security; relevance, timeliness and reliability of the received information; economic characteristics of indicators; orientation of accounting information on market components (prices, competition, threats, and risks). The urgent necessity for their organizational and methodological solution determined a research topic, the problem of the paper, its topicality and purpose.

The main purpose of the paper is to study the organizational and methodological foundations and to develop certain practical recommendations on the use of adaptive engineering approaches, tools and technologies in managing the economic security of the enterprise. The issues of increasing the adaptability of the accounting and analytical mechanisms applied for precise goals of interactive modeling and management, taking into account their specifics, the need for changes and emerging information requirements, are the foundations for the formation and functioning of the contemporary integrated information systems. As rightly noted by Richard Daft, "need for change indicates a disparity between existing and desired performance levels" (Daft \& Marcic, 2016). The development and use of adaptive engineering tools of accounting, control and analytical nature, presented by the system of derivative statement forms and derivative balance generalizations and statements allows improving the use of accounting information in management. Especially, it is true in the context of digitalization of the information support processes aimed at achieving the desired level of enterprise protection from internal and external threats, adaptation and implementation of organizational changes. The above mentioned considerations will allow accomplishing the goals and purpose of the paper and solving the specified scientific problems. 


\section{Theoretical, informational, empirical and methodological grounds of the research}

Adapting to rearrangements in the external environment of enterprise functioning presupposes not only an increased degree of interactivity and timely reaction to new market opportunities and threats; what is most importantly it presupposes interactive modeling and forecasting the future, as well as associated opportunities, threats and risks, taking into account the multivariate development scenarios, which requires the appropriate flexibility and stability of the utilized information and analytical system and its tools. The implementation of enterprise adaptive opportunities is based on the ability of proprietors, executive board and managerial staff to make weighed and alternative decisions. At the same time, the decision-making information field is characterized by the multivariance of decisions, development scenarios, forecasting options, situations, strategic activity directions, a balanced approach to assessing existing or potential opportunities and risks related to them in the context of alternative choice of the most preferable option (Arvidsson et al., 2014).

To solve the abovementioned purposes we suggest using the adaptive engineering tools in managing economic security. The issues related to the engineering approaches, principles, mechanisms, and technologies that form the entire logical set of the engineering tools functioning in accounting, analysis, control, audit, financial and tax management are widely considered and discussed (Ivanovskaya et al., 1985, Belousov et al., 2017, Patriarca et al., 2018). Engineering methods and tools are used in maintenance adaptive capabilities of integrated information systems, allowing presenting information of various kinds to be actively exploited in management taking into account the current level of computer technologies development. The conducted research has shown that the engineering ideology of managing economic processes has developed in the following cardinal directions.

1. Financial engineering is the field involving new financial processes, strategies and solutions, mainly related to corporate finance and electronic payments: financial transactions schemes, hedging tools that ensure redistribution and risk minimization, capital management, financial resources and cash flows management (Weigend et al., 1997; Penza \& Bansal, 2001; Nyutu \& Bertel, 2012), and other scholars focused on these aspects.

2. Accounting engineering deals with measurements and communications of enterprise costs. Since it is a field long overdue for consideration, a wide array of researches touched upon its most urgent issues, like the use of engineering tools for management and cost accounting (Moores \& Yuen, 2001), balance engineering and engineering of cash flows (Lee \& Hong, 2002), a system of progress balance sheets, the theory of hypothetical processes and the main mechanism of accounting engineering - derivatives balance statements, a system of accounting tools for managing economic processes (Teece et al., 1997; Gourieroux et al., 2000; Teece, 2009; Manyaeva et al., 2016).

3. Control and auditing engineering is a field that applies a system of zero derivatives balance statements, determining the state of the enterprise resources and sources of their formation for the relevant specified date, using accounting and control points mechanism. The theoretical basis of control and auditing engineering was developed by Aksenova et al. $(2004,2017)$ and others.

4. Tax engineering is focused on engineering tools and mechanisms in the sphere of tax management (tax planning and forecasting, managing tax liabilities and risks), initial operators of tax bases by types of taxes, fiscal derivative balances. The previous studies made a monumental contribution to this field of science (Krokhicheva, 2003; Krokhicheva, 2004; Lekamwasam et al., 2012, Alekseeva et al., 2017).

5. Strategic engineering revolves around secondary balance generalizations of strategic direction, integrated consolidated balance sheets, strategic statements and reports used for information and analytical support of the enterprise development strategy. In literature, there have been several researches about strategic engineering (Macintosh \& Daft, 1987; Penza \& Bansal, 2001; Aksenova et al., 2004). 
6. Adaptive engineering is concerned with processes, strategies and tool solutions based on the extensive use of network capabilities and computer technologies that provide an increased degree of interactivity and adaptation to changes, timely response to new market opportunities and threats.

We contemplate that term "adaptive engineering" essentially complements the term "adaptive enterprise", first entered by "Cap Gemini Ernst \& Young". An adaptive enterprise is a business enterprise that has mastered and determinately exploits information technologies to change the enterprise culture to increase flexibility and agility of reacting to relevant changes that occur in the constantly alternating external market. Adaptive enterprises are able to develop immediate and effective solutions at the first signs of threats and opportunities in the ecosystem (i.e. market) they reside in. They implement the developed solutions straight away into the business processes of the leading office, utilizing the stable links existing in the global architecture (Elliott \& Herbert, 2002), based on the varied use of computer programs and databases of adaptive engineering tools, which allows making weighted decisions from a number of alternative ones:

- Decisions are made being based on the specific data obtained by using adaptive engineering-based computer programs;

- Decisions are made after conscientious deliberation, selecting several alternatives and elaborating the best option with certain parameters;

- Timeliness of decisions;

- maintaining a balanced approach to decision-making on changes.

The development of adaptive engineering tools originates in the system integration of strategic information systems, business processes and communication technologies (Partridge, 1996, Brynjolfsson \& Hitt, 2000, Elliott \& Herbert, 2002, Peppard \& Ward, 2004). In our opinion, adaptive engineering tools represent a system of balance generalizations and interpretations of the state and condition of the enterprise resources and their sources, the methods used and means of their obtaining, summarizing and depicting the results with access to the enterprise cost indicators, formalized on the basis of integration of accounting, analytical and control procedures in the form of derivative balances, statements and reports that allow evaluating the effectiveness of adaptive managing economic security processes and, if required, make appropriate adjustments:

- To accelerate adaptation to changing market conditions: challenges, threats, risks, and opportunities; - To interactive modeling of the future and reasonable choice of means of its achievement, step-by-step approach to the desired adaptation and security results;

- To expand the enterprise economic growth opportunities;

- To conducting organizational changes.

Organizational changes performed not as respond to the situation (peculiar to situational management) but as a result of organizational strategic prediction and forecasting (Alekseeva et al., 2017). Adaptation involves forecasting the future, drafting scenarios for the development of customer needs, competition, external conditions and everything that can affect the organization (Adizes, 1992). The abovementioned factors determine the need to use predictive accounting information and predictive reporting sheets based on adaptive engineering tools. Specific goals and directions of using resources while implementing various adaptive measures and measures to ensure enterprise economic security designate the state and dynamics variation of its cost as indicators of management effectiveness and overall business activity. In this context, economic security management is considered as the result of decisions made by enterprise proprietors, executive board and managerial staff taking into account their impacts on the enterprise value, aimed at increasing the level of its interactivity, forecasting and adaptive reactions to market changes. Indicators of enterprise economic security are a system of definite indices evaluating effectiveness of the progress and the results of its protection on the basis of the cost method (Korolev, 
2016). The validity of management decisions is determined by a clear understanding of the types, composition, sources, time and location of resources that specify the state of proprietorship. Therefore, the key indicator of the effectiveness of enterprise economic security management is a system of indices characterizing its value, i.e. aggregated and disaggregated property rates and their derivatives, calculated on the basis of the proposed adaptive engineering tools. To ensure enterprise secure functioning the engineering tools correspond to the information determinant of the implementation of the enterprise adaptive capabilities. Besides, they allow revealing the initial, intermediate and final state of the enterprise resources and sources of their formation during the implementation of adaptive and protective measures, evaluating their effectiveness using relevant balance generalizations and system-forming indicators, demonstrating the proprietorship's state and dynamics. It should be noted that the engineering tools were created and developed over the past few decades on the basis of exploiting a single information space with an orientation towards a system of property indicators.

The necessity to use a system of derivative balance generalizations and their interpretations is caused by the fact that the traditional balance sheet does not present the actual enterprise value, hence, it is subject to transformation to determine net cost. The idea of derivative balances goes back to W. Paton, the greatest American accountancy scholar of $20^{\text {th }}$ century, who proposed a property equation which looks like an equality of assets (value of proprietorship that can be converted into cash) and capital (a disaggregated index of net liabilities, i.e., free monetary resources). The adaptive engineering tools functioning is based on utilizing the leading provisions of the management paradigm, corresponding to changes in the enterprise external macro- and microenvironment, orientated toward preserving and ensuring the dynamics of such property indicators as aggregated indices of net assets and disaggregated indices of net liabilities (Manyaeva et al., 2016). The starting point of making the derivative balance is the balance sheet with a widely used system of various adjustments. The given adjustments allow describing the impact of diverse internal and external factors, adaptation results depending on the tasks to be accomplished like factors of external macro- and microenvironment, factors of formation and use of the enterprise resource potential, prices, competitive situations, challenges, threats and risks of economic security, and time horizons. As a result, the managed objects and processes in the field of enterprise economic security can be represented by Fig. 1. Using a system of various derivative balances (including adaptive, situational, strategic, network, fractal, scenario, forecasting, control, analytical, etc.) allows organizing high-quality information and analytical support of the enterprise economic security management processes as a whole and its separate structural components based on the use of defining engineering approaches: economic situations, engineering methods and procedures, the size of accounting and management, cost value, estimated challenges and threats to economic security, risk assessment and management, property indicators and their derivatives, managing resources and sources of their formation, alternative management strategies, and multivariate solutions. The forecasting is a doubtless advantage in the modern transformation of the accounting procedures. The main methodological tool is a semantic derivative balance instrument, being a variety of computer programs, revealing the relationship between accounting, forecasting and strategic balance valuations and adaptive events groups, as depicted in the accounting framework by aggregated transactions. This approach allows calculating the performance of the net assets and liabilities, as well as determinations of the economic adaptation in the form of its active, passive, and neutral forms (Belousov et al., 2017). As a result, the set of directions and corresponding adaptive engineering tools for managing the enterprise economic security in the format of balance generalizations and interpretations can be introduced in upcoming form:

- PEST, SWOT, GAP-analysis: PEST, SWOT, GAP-analytical derivative balances;

- Management and analysis of suppliers, buyers, and competitors: resource-based, marketing, client, and conjuncture derivative balances;

- Analysis of the economic activity directions: strategic, innovative, venture, and investment derivative balances; 
- Forecasting analysis of the enterprise development scenarios: forecasting, scenario-based, situational, and alternative derivative balances;

- Market positioning, segmentation accounting, analysis and forecasting: segmental and fractal derivative balances;

- Analytical grounding for preparing and adopting management decisions: strategic, situational, and alternative derivative balances;

- Value chain analysis: sectional derivative balances;

- Estimation and analysis of the effectiveness level of adaptive measures implementation: adaptive and strategic derivative balances;

- Evaluation of the effectiveness level of implementing protective measures and measures to neutralize threats, risk management in the field of economic security: derivative balances of integrated and situational risk, hedged and immunization derivative balances;

- Solution of situational tasks and assessment of economic situations: situational, strategic, and structured derivative balances.

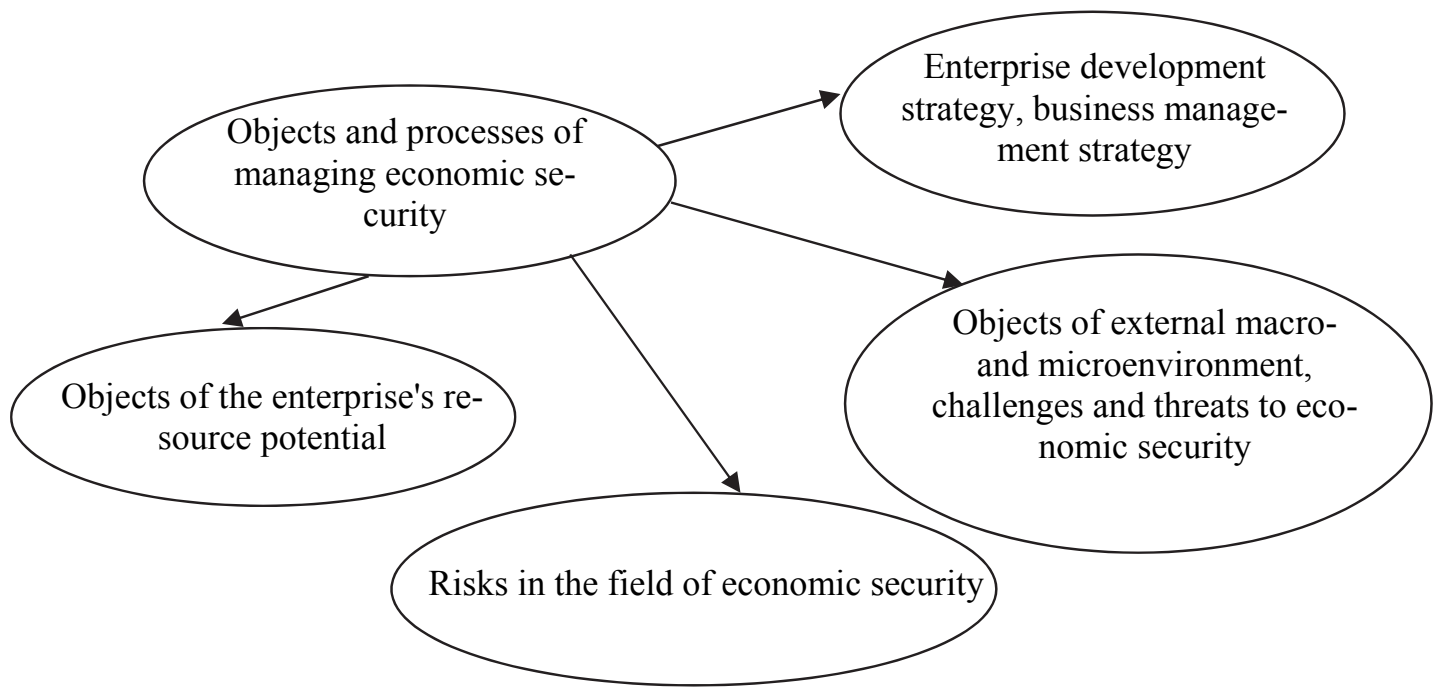

Fig. 1. Objects and processes of managing the enterprise economic security

\section{Results and discussion}

The paper substantiates the need for high-quality information and analytical support for the implementation of enterprises adaptive capabilities within the context of a constantly changing market environment of enterprises functioning and the resulting challenges and threats. Besides, the paper presents a definition of adaptive engineering tools and determines the range of urgent tasks to be solved. Beyond doubt, one of the primary requirements of an enterprise is a need for security which must be properly managed and estimated. Therefore, the paper justifies the use of the system of indicators (aggregated and disaggregated property rates), characterizing the enterprise value as a basic parameter of the management effectiveness of the enterprise economic security.

As a result of the conducted research, the authors developed a complex of the software which they highly recommend to use. They are the following: «Implementation of Adaptive Engineering Tools for Managing Enterprise Economic Security (Secure Derivative Balance)» utilized for assessing the effectiveness of supervised adaptive measures; «Singular Derivative Balance» exploited to algorithmize settlement, control and analytical procedures of economic security adaptive management; "Integration Tools for Adaptive Strategic Accounting, Control, and Analysis System» applied for systemic incorporation of accounting, control, and analysis to provide multi-variant solutions for managing enterprise adaptive strategy. Having denoted the urgency of the stated research problem, having described its theoretical, methodological, and empirical aspects, we came to the about to be mentioned results. 
We elaborated a formation and function model of the adaptive engineering tools for managing the enterprise economic security, which includes:

- The initial operator in the form of an information database of enterprise resources and their sources with the required degree of information aggregation;

- integrated use of calculation, analysis and management methods, models, and procedures;

- The organic interconnection and integration of the accounting, control and analytical blocks while making consolidated engineering balance generalizations and their interpretations;

- A system of adaptive engineering tools, based on the use of data provided by the initial operator and the accounting, control and analytical blocks of engineering information processing in the form of balance generalizations of the enterprise resources and their sources: adaptive, strategic, situational, structured, forecasting, scenario, alternative, segmental, control, analytical and other derivatives balances;

- The final operator in the form of the implementation results of adaptive measures and measures to ensure enterprise economic security: system-forming indicators and indices (net assets, net liabilities, situational components, price components, economic security zone, economic security margin, etc.);

- Taking informed decisions on managing economic security, adapting to the external environment, changing target set and indicators, ways to interact with the external environment, neutralizing threats and risks, organizational rearrangement in business, etc., based on the results obtained.

Adaptive engineering tools in the form of derivative balance structures of the enterprise resources and sources of their formation are a recommended format of engineering indicators for managing economic security. The given indicators comprise engineering situations and procedures; primary balance principles; information dimension; adjustive, aggregated and disaggregated records; accounting approaches; alternative management strategies; forecast horizon; indices of enterprise value.

The function technology of adaptive engineering tools is determined by both the appropriate algorithm for using the data maintained with initial operator's information base and the consistent implementation of accounting, control and analytical iterations:

- The initial operator in the form of economic aggregates and indicators of the relevant structural detalization and strategic orientation, which is a grouping of enterprise resources and sources of their formation in accordance with the dimension concept: balance figures, balance sheets sections, set of accounts sections, directions of economic activity, business segments, centers of responsibility, etc.

The dimensions of the information system are determined by the use of multidimensional accounting and control parameters in accordance with the requirements of the set of accounts dimensionality: time, estimation, situations, types of activities, business segments, strategic, investment, and innovation horizons;

- Accounting iterations representing adaptive, situational, forecasting, scenario, segmental, fractal, alternative, and other strategic operations, leading to a change in the composition of the enterprise resources and their sources;

- Hypothetical operations;

- Control operations;

- Analytical iterations;

- The final operator claims to be the final value indicators in the form of economic security indicators, characterizing the effectiveness level of taken and implemented measures in relation to the enterprise value.

The carried on research demonstrated that the impact evaluation of implemented adaptive and protective measures on the enterprise value is based on the engineering accounting approach "Cash / Net Liabilities" used in the formation of the basic analytical criterion and target indicators of enterprise value. It determines the effectiveness of applied strategies, decisions, alternatives, initiatives, economic situations, forecasts, scenarios, and ways to achieve the desired future with results by integrating the accounting, control and analytical procedures within a single information system: 
- Net assets as the initial state of economic security, i.e. resources and their sources. The aggregated indicator of net assets is worked out by the areas of economic activity, types of activities, activity segments, alternative development scenarios, etc.;

- Net assets and net liabilities as an intermediate or final state of resources and their sources as a result of implemented adaptive and protective measures.

The disaggregated indicator of net liabilities is settled while executing hypothetical operations of assets conditional or real sale and satisfying the enterprise liabilities in corresponding, generally, market or fair prices to obtain net cost. Using hypothetical procedures for assets conditional sale and satisfaction of liabilities in adequate assessment (market or fair) allows specifying enterprise real value and estimate the impact of price, currency, inflation, market and fair prices on property dynamics, including the possibility of obtaining price synergistic effect (Krokhicheva, 2003).

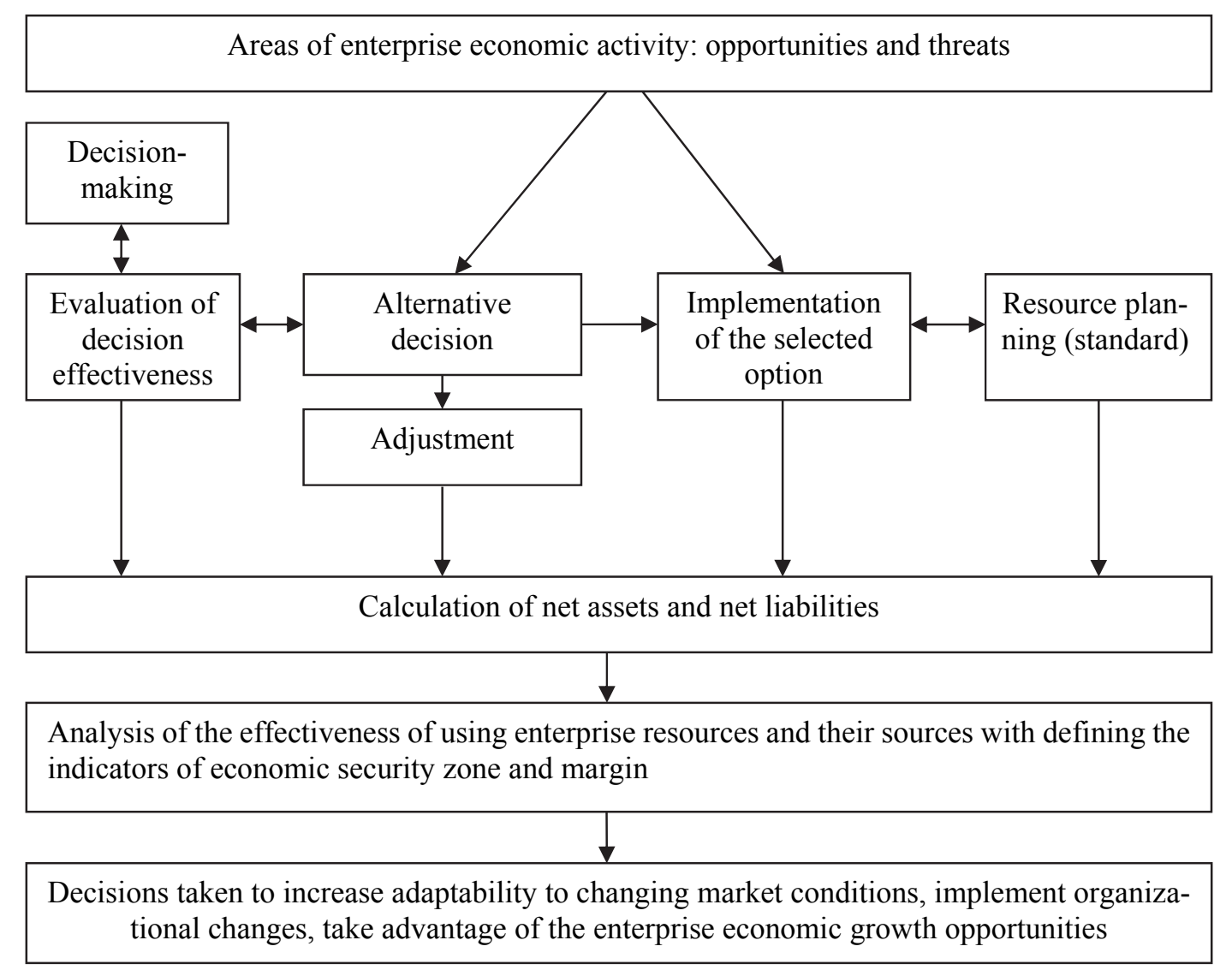

Fig. 2. The usage of results of managing enterprise economic safety based on adaptive engineering tools

Being an indicator for evaluating the effectiveness of adaptive and protective measures concerning the aggregate state of the enterprise resources and their sources, economic security zone is calculated by measuring the indices of net assets and net liabilities in various interpretations. The calculation is performed by considering the activities carried out, forecasting in the case of modeling the desired future, and taking into account the influence of various external and internal factors, paying regard to price changes):

- Active, in which there are free monetary resources that can be mobilized and used in other spheres of economic activity; 
- Passive, in which there is a lack of resources, as demand exceeds the available resources. It leads to sound decision-making about searching them.

- Neutral, characterized by a relative equality of resources and demands.

The economic security margin is calculated by comparing the values of net assets and net liabilities with the established normative resource value:

- Active, i.e. resources exceed the normative value;

- Passive is marked with lack of resources;

- Normative means a relative compliance with the normative value;

The effect of using adaptive engineering tools in managing the enterprise economic security is determined by the target goal of management and the specifics of certain tools (Fig. 2).

Therefore, the presented model exploits a vast array of adaptive engineering approaches that designate the technology and algorithmization of accounting, control and analytical procedures within the introduced blocks:

- Engineering situations (economic processes, management objects, economic situations, etc.);

- Engineering procedures (adjustments, aggregation, disaggregation, etc.);

- A valuation system (balance-based, market, fair, current, pledged, substitution, etc.);

- Dimensionality (evaluation, time, situations and events, types of activities, business segments, strategic, innovative, and investment horizons);

- aggregated records (adjustive, considering the specifics of the managed objects, control, analytical, managerial, forecasting, hypothetical, etc.);

- Alternative management strategies (cautious, conservative, moderate, moderately aggressive, and aggressive);

- Alternative operations (solving situational problems, justifying the choice of the most appropriate option from a range of alternatives, solutions based on analysis of alternatives, etc.);

- Hypothetical operations, implementation of adaptive and protective measures, achievement of desired adaptation results, factor analysis of the situational and price components impact, etc.;

- Proprietorship indicators (net assets and net liabilities);

- Control operations (at the beginning and end of the controlled period, before and after the implementation of measures, forecasting control, etc.);

- Economic aggregates (balance sheet sections, sections of set of accounts, groups of accounts, megaaccounts, the main accounting equation, depending on the aggregation degree of the initial operator data);

- Structured set of accounts (linking to the enterprise structure, adaptation to changing conditions, orientation to the adaptive engineering tools);

- System of algorithms (technology and algorithmization as complete series of the initial operator iterations, accounting, control and analytical procedures, the final operator to obtain relevant information);

- Computer programs and databases emanated from automated options of adaptive engineering tools.

Within the framework of the presented model and conducted research, we developed a methodology for accounting description and estimation of the iterative achievement of the desired adaptation result, which is accomplished within the confines of an iterative algorithm aimed at ensuring strategic forecasting:

1) Forecast evaluation of changes in the market conditions of enterprise functioning with the identification, evaluation and analysis of challenges, threats and risks in the field of economic security based on the balance sheet forecast (first change, second change, third change, etc.);

2) Statement and forecasting the entire complex of adaptive and protective measures and measures to neutralize threats in the account with drawing up an adaptive derivative balance; 
3) Adjective operations of step-by-step achieving the desired adaptation results with obtaining the adjusted adaptive balance (first stage, second stage, third stage, etc.);

4) Description of the impact of price changes by means of hypothetical processes of assets conditional sale and satisfaction of liabilities at market prices with obtaining a hypothetical derivative balance.

The presented methodology defines the technology for implementing accounting, control and analytical procedures: the enterprise development strategy; accounting aggregates and aggregated records depending on the selected initial operator; system-forming indicators and indices of enterprise economic security; accounting and control points; algorithms for sequential iterative processes; the adaptation results. The above-mentioned factors result in forming the mechanism of information and analytical groundings for the effectiveness of managing enterprise economic security. The given mechanism is devised on the basis of the adaptive engineering tools functioning, which comprises every stage of the algorithm depicted in the model, namely it includes the initial operator; aggregated records about economic processes, facts and operations; drawing up a derivative balance based on the results of aggregated records; hypothetical records displaying the processes of assets conditional sale and satisfaction liabilities; drawing up a hypothetical derivative balances based on the results of hypothetical records; final operator in the form of a system of indicators. The implementation of adaptive measures within the framework of the adopted development strategy is aimed at a qualitative solution of the task of value increment along the entire enterprise value chain (Lekamwasam et al., 2012). The enterprise strategic orientation is aimed at increasing the proprietorship indicators in accordance with the adopted development strategy, ensuring economic security and evaluating its effectiveness with respect to the enterprise value.

\section{Conclusions and Recommendations}

The program and technical implementation of the methodological guidelines on the formation and functioning of adaptive engineering tools for managing the enterprise economic security under the conditions of contemporary information systems and technologies allowed developing and offering for practical application a computer program "Implementation of the Adaptive and Engineering Tools for Managing the Enterprise Economic Security (Secure Derivative Balance)" (Schizer, 2004). The use of the given program implies its integration into a structured set of accounts considering its information and analytical base forming the system of aggregates and initial operator indicators. Furthermore, the application of appropriate technologies and algorithms of the implemented procedures creates the final operator database in the form of the obtained results. The suggested program provides systematic exploitation of traditional and engineering methods and management models and gives an opportunity to evaluate the effectiveness of adaptive measures to ensure the enterprise economic security (SWOTanalysis, GAP-analysis, PEST-analysis, competitive analysis, scenario analysis, forecast analysis, situational analysis, analysis of directions of economic activity, evaluation of the effectiveness of measures to neutralize threats), as well as to coordinate specific methods, models and management mechanisms of economic security with certain situations to develop relevant solutions:

- From the selection, information and analytical justification of the benchmarks and target indicators, plans, integrated management objects (aggregated indicators of the enterprise value, the basic analytical criterion for evaluating the effectiveness of the implemented adaptive and protective measures with regard to its cost) to specification, detailing tasks, structuring and diverging factors and situations, their detailed survey and change (deviation) cause analysis;

- From the inspection of individual managerial situations, tasks and decisions to the evaluation of common target benchmarks, solutions of system problems and situations with an orientation to the basic indicator of enterprise economic security. 
The program is focused on obtaining the final system-forming indicators, i.e. the results of implementing adaptive measures to ensure the enterprise economic security, including net assets, net liabilities, economic security zone and margin, situational and price components.

The initial operator is formed considering the information base of the structured set of accounts, the degree of information aggregation in the relevant invariance: sections or groups of accounts, balance figures or sections, other aggregated positions. Aggregated records, depicting external factors, challenges and threats, processes and operations include:

- 14 while using the set of accounts sections: 7 operations, increasing property, and 7 operations, reducing property as a result of implementing management processes;

- 8 when employing the balance sheet sections: 4 operations, intensifying property, and 4 operations, decreasing property;

- 4 at applying aggregates of the main balance equation (assets, liabilities, capital): 2 operations, increasing property, and 2 operations, reducing property respectively.

Aggregated records, describing hypothetical processes, incorporate:

- 12 while using the set of accounts sections: 6 operations, increasing property, and 6 operations, reducing property as a result of price changes;

- 8 when exploiting the balance sheet sections: 4 operations, enlarging property, and 4 operations, decreasing property due to price changes;

- 4 at employing aggregates of the main balance equation: 2 operations, increasing the property, and 2 operations, lessening property as a result of price changes.

Implementing a complex of iterations of the software algorithm within the blocks of accounting, control and analytical procedures allows obtaining the corresponding results:

- Initial operator database: aggregated indicators of net assets as the initial state of the enterprise resources and their sources;

- aggregated accounting, control, and analytical engineering operations, revealing economic processes, facts, and situations;

- drawing up a derivative balance taking into account the performed operations and obtaining the net assets index at market prices;

- Hypothetical processes, determining assets conditional sale and satisfaction of liabilities at fair prices;

- drawing up a derivative hypothetical balance and defining disaggregated indicator of net liabilities at fair prices;

- final operator database, i.e. the result of accounting, control and analytical operations, hypothetical processes, depicting the state of enterprise economic security in the form of a system of net assets and net liabilities indicators.

The use of the suggested software allows evaluating the effectiveness of the implemented adaptive measures and measures to ensure the enterprise economic security by calculating the indicators of the economic security zone and the resulting situational components. The calculations can be done by direct method, on constant basis, by chain substitution method, using the stochastic estimation method. Besides, the developed software is arranged for assessing the validity of established standards and standard resources, limit values of resources and their sources by figuring out absolute and relative indicators of the economic security margin. Within the conducted research, we developed and recommended for application software "Singular Derivative Balance" (Patent no. 2016661242). It was especially created to algorithmize the calculation, control and analytical procedures for adaptive managing the enterprise economic security. It has an undoubted advantage over similar programs, being multivariate (current results, scenarios, forecasts, alternatives, directions of economic activity). 
The software is based on the algorithmization of accounting procedures using the accounting language of situational modeling. The program exploits formulas and algorithms to generate entry of amount for the implemented adaptive and protective measures in the corresponding accounting cycle with access to property indicators to evaluate and monitor the adaptation results. The use of singular derivative balances creates a closed agility cycle. The basic steps are sensing a threat or opportunity, strategizing about options, deciding on the most appropriate action, and then communicating it before acting. This cycle must be continuous, because each change must be monitored for subsequent changes (Taylor \& Raden, 2007). Moreover, we developed software "Integration Tools for the Adaptive System of Strategic Accounting, Control, and Analysis" (Patent no. 2016661163) to standardize the processes of strategic accounting, control, and analysis. The suggested software allows producing a complex of adaptive engineering tools in the form of a system of derivative balances and their combinations: PEST-analytical, SWOT-analytical, GAP-analytical, structured, strategic, scenario, forecast, and situational ones. The key purpose of the program is to implement a set of accounting and analytical procedures of the systematic integration of strategic accounting, control and analysis processes based on a single integration tool in the form of a system of strategic-oriented derivative balance generalizations to ensure the solution multivariance for managing enterprise adaptive strategy. The software provides an opportunity to design an integrated system of strategic accounting, control and analysis of adaptation factors, indicating probability characteristics and solving a wide array of assessment problems.

The practical application of the given program involves the use of specific engineering methods and derivative balances for various management purposes. For instance, GAP-analysis of the situation and its possible solutions is exploited to bridge the gap by mobilizing appropriate resources using the GAPanalytical derivative balance and obtaining the following results: the value of strategic gap (active, passive, zero), price strategic effect, economic security margin (active, passive, standard), a validity assessment of the established standards. Utilizing GAP-analysis could be proposed and recommended to interested users (executive board, managers, etc.) to bridge the gap on the basis of identified strategic initiatives. The gap value is determined by a sequential comparison of the obtained indicators of net assets, depicting presented ones in the iteration derivative balance. The software offered for practical application provides a relevant assessment of the effectiveness of adaptive and protective measures in the field of enterprise economic to make informed management decisions aimed at reducing hazards and threats to an acceptable level; to eliminate existing and potential threats; to prevent damage from the possible threats; to recover losses from security threats; to implement existing and potential development opportunities and initiatives, directions of the enterprise economic activity.

The practical significance of the study comprises an integration of traditional and engineering methods and tools of information and analytical support of the processes of strategic forecasting, adapting and managing of enterprise economic security, based on adaptive engineering tools. Widely exploiting them, proprietors, executive boars and managerial staff will obtain the required information about the status of indicators of the economic security system in the requested context regarding enterprise vital economic interests and their implementation.

\section{References}

Adizes, I. (1992). Mastering change: the power of mutual trust and respect in personal life, family life, business and society. The Adizes Institute Publishing.

Aksenova, E. A., Lazutina, A. A., \& Sokolov, A. V. (2004). Study of a non-markovian stack management model in a two-level memory. Programming and Computer Software, 30(1), 25-33.

Alekseeva, I. V., Evstafyeva, E. M., Kruchanova, Y. A., \& Krokhicheva, G. E. (2017). Strategic Reporting Methodology and its Reliability Audit. European Research Studies, 20(3B), 333..

Armstrong, S., \& Mitchell, B. (2008). Essential HR Handbook: A Quick and Handy Resource for Any Manager or HR Professional. Red Wheel/Weiser. 
Arvidsson, V., Holmström, J., \& Lyytinen, K. (2014). Information systems use as strategy practice: A multi-dimensional view of strategic information system implementation and use. The Journal of Strategic Information Systems, 23(1), 45-61.

Belousov, A. I., Mikhailova, G. V., Uzdenova, F. M., \& Blokhina, V. G. (2017). Accounting engineering tools in the research of economic costs and benefits. European Research Studies, 20(3B), 13.

Brynjolfsson, E., \& Hitt, L. M. (2000). Beyond computation: Information technology, organizational transformation and business performance. Journal of Economic perspectives, 14(4), 23-48.

Daft, R. L., \& MacIntosh, N. B. (1978). A new approach to design and use of management information. California Management Review, 21(1), 82-92.

Daft, R. L., \& Marcic, D. (2016). Understanding management. Nelson Education.

Elliott, T., \& Herbert, D. (2002). Joined-up Systems: Building the Integrated Business. Hodder \& Stoughton Educational Division.

Gourieroux, C., Laurent, J. P., \& Scaillet, O. (2000). Sensitivity analysis of values at risk. Journal of Empirical Finance, 7(3-4), 225-245..

Ivanovskaya, T. A., Arakelyants, M. M., Tsipurskii, S. I., \& Veis, A. F. (1985). New data on the Riphean of the Mokui parametric well (southeastern yakutia). Lithol. Miner. Resour.(Engl. Transl.);(United States), 19(6).

Korolev, A. (2016). Systemic balancing and regional Hedging: China-Russia relations. The Chinese Journal of International Politics, 9(4), 375-397..

Krokhicheva, G.E. (2003). Virtual Accounting: concepts, theory and practice. Moscow: Finances and Statistics, 176(3). 1-52.

Krokhicheva, G.E, (2004). Virtual accounting: concepts, modelling and organization. Journal of Empirical Finance, 9(1), 25-45.

Lee, S. M., \& Hong, S. (2002). An enterprise-wide knowledge management system infrastructure. Industrial Management \& Data Systems, 102(1), 17-25.

Lekamwasam, S., Adachi, J. D., Agnusdei, D., Bilezikian, J., Boonen, S., Borgström, F., ... \& Kanis, J. A. (2012). A framework for the development of guidelines for the management of glucocorticoidinduced osteoporosis. Osteoporosis International, 23(9), 2257-2276..

Macintosh, N. B., \& Daft, R. L. (1987). Management control systems and departmental interdependencies: an empirical study. Accounting, Organizations and Society, 12(1), 49-61.

Manyaeva, V., Piskunov, V., \& Fomin, V. (2016). Strategic management accounting of company costs. European Research Studies Journal, 45(6), 88-108.

Moores, K., \& Yuen, S. (2001). Management accounting systems and organizational configuration: a life-cycle perspective. Accounting, Organizations and Society, 26(4-5), 351-389.

Nyutu, P. N., \& Bertel, J. M. (2012). Perceptions of teacher preparation and attitudes regarding students' mental health in Kenya. Advances in School Mental Health Promotion, 5(1), 63-74.

Partridge, C. (1996). Business objects: re-engineering for re-use. Butterworth-Heinemann.

Patriarca, R., Bergström, J., Di Gravio, G., \& Costantino, F. (2018). Resilience engineering: Current status of the research and future challenges. Safety Science, 102, 79-100.

Penza, P., \& Bansal, V. K. (2001). Measuring market risk with value at risk (Vol. 17). John Wiley \& Sons.

Peppard, J., \& Ward, J. (2004). Beyond strategic information systems: towards an IS capability. The Journal of Strategic Information Systems, 13(2), 167-194.

Schizer, D. M. (2004). Balance in the taxation of derivative securities: An agenda for reform. Columbia Law Review, 104(1886), 56-68.

Shifrin, M.B. (2006). Strategicheskij mene dgment [Strategic management], Piter, St. Peters burg, Russia. Стаття надійшла до редакиіï, 20(10),. 23-45.

Taylor, J., \& Raden, N. (2007). Smart Enough Systems: How to Deliver Competitive Advantage by Automating Hidden Decisions. Pearson Education.

Teece, D. J. (2009). Dynamic capabilities and strategic management: Organizing for innovation and growth. Oxford University Press on Demand. 
Teece, D. J., Pisano, G., \& Shuen, A. (1997). Dynamic capabilities and strategic management. Strategic management journal, 18(7), 509-533.

Weigend, A. S. (1997). Decision technologies for financial engineering. Y. Abu-Mostafa, \& A. P. N. Refenes (Eds.). New York, NY: World Scientific.

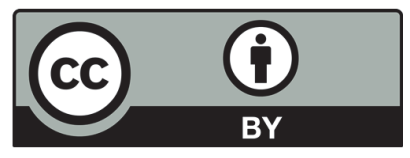

(C) 2018 by the authors; licensee Growing Science, Canada. This is an open access article distributed under the terms and conditions of the Creative Commons Attribution (CC-BY) license (http://creativecommons.org/licenses/by/4.0/). 